\title{
Diagnostic accuracy of surface coil magnetic resonance imaging at 1.5 T for local staging of elevated risk prostate cancer
}

\author{
Brian Kim, MD; ; Rodney H. Breau, MD, FRCSC,; Demetri Papadatos, MD, FRCPC, ${ }^{+}$Dean Fergusson, PhD;, \\ Steve Doucette, MSc, ${ }^{\neq}$Ilias Cagiannos, MD, FRCSC; Chris Morash, MD, FRCSC*
}

\section{Abstract}

Introduction: Preoperative prostate cancer stage predicts prognosis and affects treatment decisions. The purpose of this study was to estimate the sensitivity and specificity of surface coil magnetic resonance imaging (MRI) for prostate cancer stage using surgical pathologic data as the reference standard.

Methods: High-risk patients ( $\geq \mathrm{cT} 3$ or PSA $\geq 20 \mathrm{ng} / \mathrm{mL}$ or Gleason $\geq 8$ ) and selected intermediate-risk patients (clinically bulky disease on exam or biopsy, cT2b/c, or Gleason 7 with $\geq 3$ of 5 biopsy cores positive in a lobe) routinely received a pelvic MRI at our institution. The images of identified patients were reviewed by one radiologist who was blinded to clinical information. The radiologist reported presence or absence of tumour within each lobe of the prostate. Extraprostatic extension (EPE), seminal vesicle (SV) invasion and pelvic lymph node (PLN) metastasis were also reported. Radiological findings were compared with prostatectomy pathology reports.

Results: During the study period, about 320 radical prostatectomies were performed. Of these, 32 had a preoperative surface coil pelvic MRI adequate for analysis. Pathologically, 53 of 64 $(82.8 \%)$ prostate lobes contained tumour, 17 (26.6\%) lobes had associated EPE, 12 (18.8\%) had SV involvement and 7 (10.9\%) sets of PLNs contained cancer. Magnetic resonance imaging sensitivity and specificity were, respectively, $94.3 \%$ and $81.8 \%$ for tumour location, $82.4 \%$ and $87.2 \%$ for EPE, $83.3 \%$ and $92.3 \%$ for SV invasion and $71.4 \%$ and $94.7 \%$ for PLN involvement.

Interpretation: Surface coil MRI accurately stages many prostate cancer patients with elevated risk of extraprostatic disease. This mode of imaging may be reasonable at centres that do not have endorectal coil MRI.

\section{Résumé}

Introduction : Le stade du cancer de la prostate avant l'opération permet d'établir le pronostic et influe sur les décisions en ce qui concerne le traitement. Notre étude avait pour objectif d'évaluer la sensibilité et la spécificité de l'imagerie par résonance magnétique avec bobine de surface dans l'établissement du stade du cancer de la prostate en utilisant les données pathologiques liées à la chirurgie comme données de référence.

Méthodologie : Les patients à risque élevé (tumeur $\geq \mathrm{CT} 3$ ou taux $\mathrm{d}^{\prime} \mathrm{APS} \geq 20 \mathrm{ng} / \mathrm{mL}$ ou score de Gleason $\geq 8$ ) et certains patients à risque intermédiaire (maladie volumineuse sur le plan clinique lors de l'examen ou à la biopsie, tumeur cT2b/c, ou score de Gleason de 7 avec au moins 3 carottes biopsiques sur 5 prélevées dans le même lobe qui soient positives) subissent un examen par IRM de façon systématique à notre établissement. Les images des patients inclus dans l'étude ont été examinées par un radiologiste à qui les données cliniques n'avaient pas été divulguées (examen à l'insu). Le radiologiste signalait la présence ou l'absence de tumeur dans chaque lobe prostatique. On a aussi signalé des cas d'extension extraprostatique, d'envahissement des vésicules séminales et de métastases touchant les ganglions lymphatiques pelviens. Les observations radiologiques ont été comparées aux résultats des rapports de pathologie suivant la prostatectomie.

Résultats : Pendant l'étude, environ 320 prostatectomies radicales ont été réalisées. De ce nombre, 32 patients avaient subi une IRM pelvienne avec bobine de surface dont les données étaient analysables. À l'examen pathologique, 53 des 64 lobes prostatiques $(82,8 \%)$ présentaient du tissu tumoral, 17 lobes $(26,6 \%)$, une extension extraprostatique associée, 12 (18,8 \%), un envahissement des vésicules séminales et 7 (10,9\%), des groupes de ganglions lymphatiques pelviens présentant des traces de cancer. La sensibilité et la spécificité de l'IRM étaient respectivement, de 94,3\% et de $81,8 \%$ pour l'emplacement de la tumeur, de $82,4 \%$ et 87,2 $\%$ pour les extensions extraprostatiques, de $83,3 \%$ et $92,3 \%$ pour les envahissements des vésicules séminales et de $71,4 \%$ et $94,7 \%$ pour l'atteinte des ganglions lymphatiques pelviens.

Interprétation : L'IRM avec bobine de surface permet d'établir avec exactitude le stade du cancer de la prostate chez de nombreux patients présentant un risque accru de maladie extraprostatique. Cette technique d'imagerie pourrait représenter une méthode diagnostique raisonnable dans les centres qui ne disposent pas d'IRM avec bobine endorectale.

Can Urol Assoc J 2010;4(4):257-62

\section{Introduction}

Prostate cancer is the most common non-cutaneous cancer in Canadian men and is one of the most common causes of cancer-related death. ${ }^{1}$ Pre-treatment disease assessment allows for prognostication prior to therapy. However, even nomograms based on large data sets can be inaccurate in certain individuals. For this reason, some centres advocate preoperative endorectal coil magnetic resonance imaging (MRI) in patients at highest risk for locally advanced disease. ${ }^{2}$ The primary objectives of endorectal MRI are to better assess the extent of local disease and to guide surgical planning. 
Kim et al.

\begin{tabular}{|c|c|c|c|}
\hline & All patients & $\begin{array}{l}\text { Intermediate } \\
\text { risk }\end{array}$ & High risk \\
\hline No. patients & 32 & 10 & 22 \\
\hline Average age (yrs) & $59.1 \pm 6.7$ & $57.1 \pm 7.5$ & $60.1 \pm 6.2$ \\
\hline \multicolumn{4}{|l|}{$\begin{array}{l}\text { Preoperative PSA } \\
\text { (ng/mL) }\end{array}$} \\
\hline$<10$ & $22(68.8)$ & $5(15.6)$ & $17(53.1)$ \\
\hline$* 10$ to $<20$ & $5(15.6)$ & $5(15.6)$ & 0 \\
\hline$* 20$ & $5(15.6)$ & --- & $5(15.6)$ \\
\hline \multicolumn{4}{|c|}{ Biopsy Gleason sum } \\
\hline 6 & $3(9.4)$ & $0(0.0)$ & $3(9.4)$ \\
\hline 7 & $13(40.6)$ & $10(31.3)$ & $3(9.4)$ \\
\hline$\geq 8$ & $16(50.0)$ & --- & $16(50.0)$ \\
\hline \multicolumn{4}{|l|}{ Clinical T-stage } \\
\hline cT1b & $1(3.1)$ & $1(3.1)$ & 0 \\
\hline $\mathrm{cT} 1 \mathrm{c}$ & $9(28.1)$ & $2(6.3)$ & $7(21.9)$ \\
\hline cT2a & $10(31.3)$ & $3(9.4)$ & 7 (21.9) \\
\hline $\mathrm{cT} 2 \mathrm{~b}$ & $6(18.8)$ & $4(12.5)$ & $2(6.3)$ \\
\hline $\mathrm{cT} 2 \mathrm{c}$ & 0 & 0 & 0 \\
\hline ст3а & $5(15.6)$ & --- & $5(15.6)$ \\
\hline cT3b & $1(3.1)$ & -- & $1(3.1)$ \\
\hline \multicolumn{4}{|c|}{ Pathological T-stage } \\
\hline pT2a & $7(21.9)$ & $2(6.3)$ & $5(15.6)$ \\
\hline pT2b & $1(3.1)$ & $1(3.1)$ & 0 \\
\hline pT2c & $8(25.0)$ & $3(9.4)$ & $5(15.6)$ \\
\hline рТЗа & $8(25.0)$ & $2(6.3)$ & $6(18.8)$ \\
\hline рТ3b & $8(25.0)$ & $2(6.3)$ & $6(18.8)$ \\
\hline
\end{tabular}

Despite the utility of endorectal coil MRI, its widespread use is prohibited by cost and availability. Surface coil MRI is more commonly available in Canada and allows for simultaneous assessment of pelvic lymph nodes (PLNs). While previous studies demonstrate superior accuracy of endorectal coil compared with surface coil MRI, these findings may not be applicable to a contemporary cohort of patients. Imaging technology and data processing have improved significantly since these investigations and the impact of these advances on diagnostic accuracy have not been adequately assessed. The purpose of this study was to assess the performance of contemporary surface coil MRI for prostate cancer stage using surgical pathologic data as the reference standard.

\section{Methods}

Consecutive patients with biopsy-proven prostate adenocarcinoma referred to the Ottawa Hospital, Ottawa, Ontario, Canada, urologic-oncology service from January 2003 to December 2006 were considered for study enrolment. We selected all patients with high-risk disease $(\geq \mathrm{CT} 3$ or prostate-specific antigen $[\mathrm{PSA}] \geq 20 \mathrm{ng} / \mathrm{mL}$ or Gleason $\geq 8$ ) and intermediate-risk disease (clinically bulky disease, cT2b/c, or Gleason 7 with $\geq 3 / 5$ biopsy cores positive in a lobe) to receive a surface coil MRI. Patients were excluded from the study if they had low-risk prostate adenocarcinoma and/or received neoadjuvant androgen ablation therapy.

Utilizing a 1.5-Tesla (T) whole-body MRI (Siemens Symphony, Malvern, PA), MR 2004A software, and a pelvic phased-array surface coil, T1- and T2-weighted images were obtained in the axial, sagittal and coronal planes. For T2-weighted fast spin-echo sequences, the following parameters were applied: repetition time/echo time $=5100 / 102 \mathrm{~ms}$, turbo factor $=19$, matrix $=512 \times 408$, field of view $=18 \mathrm{~cm}$, slice thickness $=5 \mathrm{~mm}$, and scan time $=2$ minutes.

Surface coil MRI images were analyzed retrospectively by a radiologist (DP) experienced in pelvic MRI, who was blinded to clinical and pathological details of the patients apart from the diagnosis of prostate cancer. Each prostate lobe was examined separately for the presence or absence of tumour, the presence of extraprostatic extension (EPE), seminal vesicle (SV) invasion and PLN involvement.

Tumour in prostate was predicted by homogenous low signal intensity as visualized on T2-weighted images, in contrast to the higher intensity peripheral zone tissue. ${ }^{3}$ Extraprostatic extension was suggested when asymmetry of the neurovascular bundle, obliteration of the rectoprostatic angle, thickening of the prostate capsule or stranding into the periprostatic fatty tissue was present. ${ }^{4-6}$ Tumour in the SV was suggested by presence of low signal-intensity, causing dilatation and asymmetry of the gland. ${ }^{6}$ Malignant PLNs were suggested by an enlarged size ( $>6 \mathrm{~mm}$ in the short axis) and spherical shape. ${ }^{7}$

\begin{tabular}{|c|c|c|c|c|c|c|c|c|}
\hline & TP & TN & FP & FN & $\begin{array}{c}\text { Sensitivity } \\
(\%)\end{array}$ & $\begin{array}{c}\text { Specificity } \\
(\%)\end{array}$ & $\begin{array}{l}\text { PPV } \\
(\%)\end{array}$ & $\begin{array}{l}\text { NPV } \\
(\%)\end{array}$ \\
\hline All patients $(n=64)$ & 50 & 9 & 2 & 3 & $\begin{array}{c}94.3 \\
(84.3-98.8) \\
\end{array}$ & $\begin{array}{c}81.8 \\
(48.2-97.7) \\
\end{array}$ & $\begin{array}{c}96.2 \\
(86.8-99.5) \\
\end{array}$ & $\begin{array}{c}75.0 \\
(42.8-94.5) \\
\end{array}$ \\
\hline Intermediate risk $(n=20)$ & 15 & 4 & 0 & 1 & $\begin{array}{c}93.8 \\
(69.8-99.8)\end{array}$ & $\begin{array}{c}100 \\
(39.8-100)\end{array}$ & $\begin{array}{c}100 \\
(78.2-100)\end{array}$ & $\begin{array}{c}80.0 \\
(28.4-99.5)\end{array}$ \\
\hline High risk $(n=44)$ & 35 & 5 & 2 & 2 & $\begin{array}{c}94.6 \\
(81.8-99.3)\end{array}$ & $\begin{array}{c}71.4 \\
(29.0-96.3)\end{array}$ & $\begin{array}{c}94.6 \\
(81.8-99.3)\end{array}$ & $\begin{array}{c}71.4 \\
(29.0-96.3)\end{array}$ \\
\hline
\end{tabular}




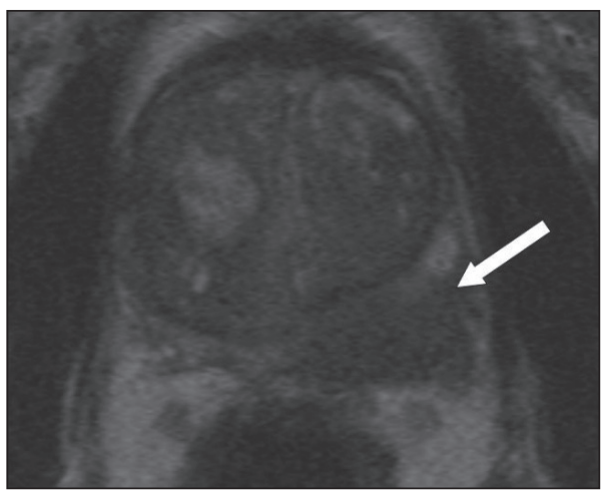

Fig. 1. Axial T2weighted magnetic resonance image of the prostate and surrounding tissue. Arrow indicates low intensity tumour with gross extraprostatic extension.

No patients were excluded from surgery based on MRI findings. All had a retropubic radical prostatectomy by 1 of 2 urologists (IC and CM) who were fellowship-trained in urologic oncology. Cavernosal nerve-sparing was performed if the risk of EPE into the neurovascular bundle was considered acceptably low based on biopsy and imaging findings.

Radical prostatectomy specimens were coated with India ink and fixed in a 10\% neutral buffered formaldehyde solution for 24 hours and sectioned in the axial plane at 4-mm intervals. Tissue sections were embedded in paraffin blocks and sectioned at 4- $\mu \mathrm{m}$ intervals for staining with hematoxylin and eosin. Specimens were reviewed for final pathological determination by experienced genitourinary histopathologists blinded to MRI data, using the 2002 TNM classification system. ${ }^{8}$

A single-blinded investigator (RB) and statisticians (DF and SD) carried out the final analysis, correlating pathological and radiological findings for: tumour in prostate; presence of EPE; SV invasion; and PLN involvement, in a side-specific fashion. Sensitivities, specificities, positive predictive values (PPV) and negative predictive values (NPV) of the above categories were determined for all patients according to risk grouping. A power analysis was not performed as the focus of the study was intended to be a feasibility case series.

\section{Results}

During the study period, about 320 radical prostatectomies were performed. Fourty patients met inclusion criteria, which included all high-risk and select intermediate-risk patients. We excluded patients with low risk disease and patients who underwent neoadjuvant androgen ablation therapy. All participants had a pre-operative surface coil MRI. Unfortunately, 8 patients were excluded from the study due to inadequate T2-weighted images.

Of the 32 remaining patients, 10 and 22 had intermediate- and high-risk disease preoperatively, respectively (Table 1 ). The average patient age was $59 \pm 6.7$. All patients in the intermediate-risk group had a Gleason sum of 7 with clinical tumour stages ranging from $\mathrm{cT} 1 \mathrm{~b}$ to $\mathrm{cT} 2 \mathrm{~b}$. Of the high-risk patients, 16 had a Gleason sum $\geq 8 ; 5$ had a PSA value $\geq 20 \mathrm{ng} / \mathrm{mL}$; and 6 were clinical stage $\geq c T 3$.

Histopathological results after radical prostatectomy revealed that 16 of 32 patients had locally advanced disease ( $\geq$ pT3), 4 and 12 of whom were considered preoperatively to have intermediate- and high-risk disease, respectively.

\section{Tumour within the prostate}

The prevalence of tumour within the prostatic lobes was $82.8 \%$ (53/64 lobes; 25 left, 28 right). Surface coil MRI was $94.3 \%$ (95\% Cl: 84.3 to 98.8 ) sensitive for tumour within the prostate and had correspondingly accurate positive predictive values (Table 2). The associated specificity and negative predictive values for the presence of tumour were $81.8 \%$ and $75.0 \%$, respectively, with wide confidence intervals. Overall, surface coil MRI correctly predicted presence or absence of a tumour in 59 of 64 lobes. Diagnostic accuracy seemed consistent between risk groups.

\section{Extraprostatic extension}

Pathologic analysis revealed 26.6\% (17/64; 7 left, 10 right) of prostatic lobes had associated extraprostatic extension. Overall, surface coil MRI tended to overcall EPE as is reflected by a $70.0 \%(95 \% \mathrm{Cl}: 45.7$ to 88.1$)$ PPV and a $93.2 \%$ (95\% Cl: 81.3 to 98.6) NPV (Table 3). Surface coil MRI correctly predicted the presence or absence of EPE in 41 of 44 high-risk patient lobes compared with 14 of 20 intermediate patient lobes.

\begin{tabular}{|c|c|c|c|c|c|c|c|c|}
\hline & TP & TN & FP & FN & $\begin{array}{c}\text { Sensitivity } \\
\text { (\%) }\end{array}$ & $\begin{array}{c}\text { Specificity } \\
\text { (\%) }\end{array}$ & $\begin{array}{l}\text { PPV } \\
(\%)\end{array}$ & $\begin{array}{l}\text { NPV } \\
(\%)\end{array}$ \\
\hline All patients $(n=64)$ & 14 & 41 & 6 & 3 & $\begin{array}{c}82.4 \\
(56.6 .-96.2)\end{array}$ & $\begin{array}{c}87.2 \\
(74.3-95.2)\end{array}$ & $\begin{array}{c}70.0 \\
(45.7-88.1)\end{array}$ & $\begin{array}{c}93.2 \\
(81.3-98.6)\end{array}$ \\
\hline Intermediate risk $(n=20)$ & 2 & 12 & 4 & 2 & $\begin{array}{c}50.0 \\
(6.8-93.2)\end{array}$ & $\begin{array}{c}77.8 \\
(52.4-93.6)\end{array}$ & $\begin{array}{c}33.3 \\
(4.33-77.7)\end{array}$ & $\begin{array}{c}85.7 \\
(57.2-98.2)\end{array}$ \\
\hline High risk $(n=44)$ & 12 & 29 & 2 & 1 & $\begin{array}{c}92.3 \\
(64.0-99.8)\end{array}$ & $\begin{array}{c}93.1 \\
(77.2-99.2)\end{array}$ & $\begin{array}{c}85.7 \\
(57.2-98.2)\end{array}$ & $\begin{array}{c}96.7 \\
(82.8-99.9)\end{array}$ \\
\hline
\end{tabular}

$\mathrm{TP}=$ true positive $\mathrm{TN}=$ true negative; $\mathrm{FP}=$ false positive; $\mathrm{FN}=$ false negative; $\mathrm{PPV}=$ positive predictive values; $\mathrm{NPV}=$ negative predictive values. 
Kim et al.

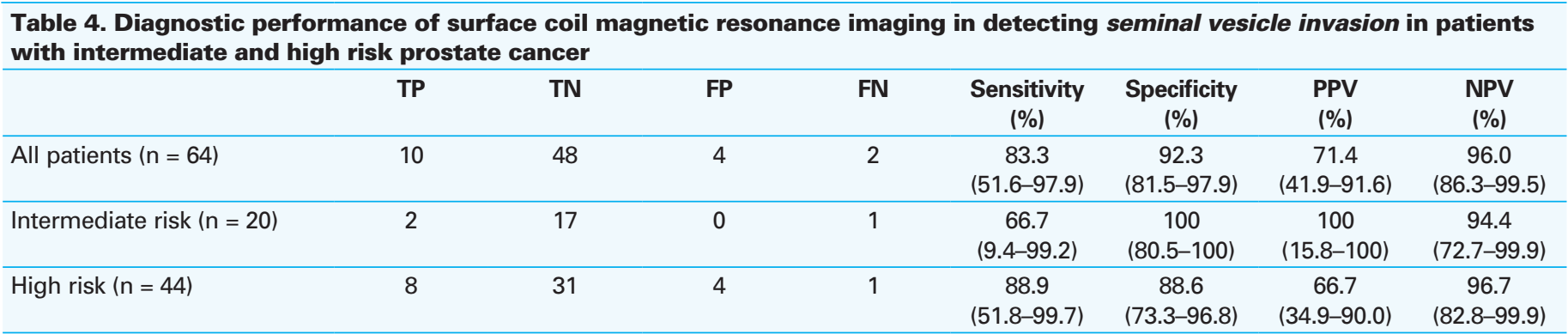

$\mathrm{TP}=$ true positive $\mathrm{TN}=$ true negative; $\mathrm{FP}=$ false positive; $\mathrm{FN}=$ false negative; $\mathrm{PPV}=$ positive predictive values; $\mathrm{NPV}=$ negative predictive values

\section{Seminal vesicle involvement}

Twelve of 64 seminal vesicles contained tumour $(19 \%, 6$ left, 6 right). As was observed for EPE, SVI tended to be overcalled (Table 4). Diagnostic accuracy for SVI seemed to be comparable between risk strata.

\section{Pelvic lymph node involvement}

Only 5 patients had PLN involvement (7/64 sides; 2 left, 5 right). Overall, surface coil MRI accurately predicted presence or absence of metastatic lymph node disease in 59 of 64 nodal areas (Table 5).

\section{Discussion}

Recent prostate cancer imaging initiatives have focused on new technology, such as magnetic resonance spectroscopy and dynamic contrast enhanced MRI, however, it will be many years before these tests will be available to most clinicians. ${ }^{9-13}$ In this study, surface coil MRI, a more widely available imaging technique, was a reasonably accurate predictor of tumour stage in patients with adverse prognostic features for locally advanced disease. Thus, in centres without an endorectal coil or more advanced technologies, surface coil MRI seems to be a useful alternative preoperative investigation in select patients.

Magnetic resonance imaging has been used in several centres to better characterize the local extent of prostate cancer and is more accurate than computed tomography or ultrasound. ${ }^{14,15}$ Initial body-coil MRI studies were limited by poor spatial and contrast resolutions, with reported accuracies as low as 77\%. ${ }^{15-18}$ As a result, an endorectal coil was developed to better visualize the zonal architecture of the prostate and tumour in the periprostatic tissue and SVs. ${ }^{19}$ Engelbrecht and colleagues found endorectal coil superiority in their meta-analysis, however, a similar systematic review revealed no difference between body and endorectal coil images. ${ }^{20,21}$ The proximity of the endorectal coil to the prostate resulted in improved resolution and decreased signal artefact. However, the small field of view precludes assessment of the pelvic bones or PLNs and the rectal probe distorts the prostate. Thus, endorectal coil MRI, alone or in conjunction with surface coil MRI, has been adopted in many centres in the United States.

In our patient cohort, surface coil MRI was highly sensitive for tumours in the prostate gland $(94.3 \%)$. Other trials have reported a wide range of sensitivities (37 to 96\%) for the detection and correct localization of disease. ${ }^{22}$ This variance may be explained by tumour location and size. When tumours are located within the central zone, the natural heterogeneity of the gland makes tumour depiction difficult. Furthermore, despite technological advances, MRI seems limited for the detection of small tumours. The high sensitivity in our series is likely due to relatively large tumours. While not assessed in the current study, MRI may not be beneficial in low-risk patients and generalizations should only be applied to select intermediate- and high-risk patients.

Prediction of side-specific extraprostatic disease is extremely important as it can aid the urologist in the decision to spare the cavernosal nerves or widely resect the periprostatic tissue. In this study, surface coil MRI was both

\begin{tabular}{|c|c|c|c|c|c|c|c|c|}
\hline & TP & TN & FP & FN & $\begin{array}{c}\text { Sensitivity } \\
(\%)\end{array}$ & $\begin{array}{c}\text { Specificity } \\
(\%)\end{array}$ & $\begin{array}{l}\text { PPV } \\
(\%)\end{array}$ & $\begin{array}{c}\text { NPV } \\
\text { (\%) }\end{array}$ \\
\hline All patients $(n=64)$ & 14 & 41 & 6 & 3 & $\begin{array}{c}71.4 \\
(29.0-96.3)\end{array}$ & $\begin{array}{c}94.7 \\
(85.4-98.9)\end{array}$ & $\begin{array}{c}62.5 \\
(24.5-91.5)\end{array}$ & $\begin{array}{c}96.4 \\
(86.6-99.6)\end{array}$ \\
\hline Intermediate risk $(n=20)$ & 2 & 12 & 4 & 2 & $\begin{array}{c}100 \\
(2.5-100) \\
\end{array}$ & $\begin{array}{c}94.7 \\
(74.0-99.9)\end{array}$ & $\begin{array}{c}50.0 \\
(1.3-98.7)\end{array}$ & $\begin{array}{c}100 \\
(81.5-100)\end{array}$ \\
\hline High risk $(n=44)$ & 12 & 29 & 2 & 1 & $\begin{array}{c}66.7 \\
(22.3-95.7)\end{array}$ & $\begin{array}{c}94.7 \\
(82.3-99.4)\end{array}$ & $\begin{array}{c}66.7 \\
(22.3-95.7)\end{array}$ & $\begin{array}{c}94.7 \\
(82.3-99.4)\end{array}$ \\
\hline
\end{tabular}

$\mathrm{TP}=$ true positive; $\mathrm{TN}=$ true negative; $\mathrm{FP}=$ false positive; $\mathrm{FN}=$ false negative; $\mathrm{PPV}=$ positive predictive values; $\mathrm{NPV}=$ negative predictive values 
sensitive and specific for EPE, particularly in patients with high-risk features. Currently, prostate cancer stage prediction is based on digital rectal exam findings, preoperative PSA values and prostate biopsy histology. Several large data sets have confirmed the predictive value of these disease features and they have been incorporated into various pre-treatment nomograms, tables and algorithms. ${ }^{23-25}$ Furthermore, side-specific nomograms for EPE have helped define the laterality of EPE, with predictive accuracies of 81 to $84 \% .^{26-28}$ However, nomograms are inadequate to direct surgical approach in the common situation when a patient has an intermediate risk of EPE. For example, in this study, one patient had a PSA of $9.9 \mathrm{ng} / \mathrm{mL}$, cT3b, Gleason 3+3 adenocarcinoma in $20 \%$ of biopsy cores. The nomogramcalculated risk for left-sided EPE was 28\%. ${ }^{26}$ In this patient, surface coil MRI was useful, as EPE was suggested on MRI and confirmed pathologically. Indeed, recent studies have demonstrated an improvement in predicting EPE when combining MRI findings with nomograms and clinical variables, such as PSA, Gleason score and clinical stage. ${ }^{29,30}$ However, it is not feasible to perform preoperative MRI on all prostate cancer patients. Therefore, if the diagnostic performance of surface coil MRI is validated in larger studies, testing thresholds could be calculated based on side-specific pretest probabilities to help clinicians determine which patients could benefit from preoperative imaging. ${ }^{27,31}$

Consistent with other studies, surface coil MRI was highly specific and reasonably sensitive in predicting tumour involvement of the SV. Allen and colleagues reported 100\% specificity in detecting SV invasion, however, this study similarly had a low incidence of events (6 cases). ${ }^{32}$ Engelbrecht and colleagues performed a meta-analysis on the local staging of prostate using MRI (with and without an endorectal coil) and found a joint maximum sensitivity and specificity of $82 \%$ for SV invasion from the summary receiver operating characteristic (ROC) curve. ${ }^{33}$ While the performance of surface coil MRI in predicting SV invasion seems favourable, the low incidence of events in all series necessitates caution when interpreting these findings.

As stated for SV invasion, the utility of MRI in PLN prediction remains unclear given the low prevalence of this pathologic finding. We observed high sensitivity and intermediate specificity in the prediction of PLN metastases. Hövels and colleagues demonstrated a pooled specificity of $82 \%$ and sensitivity of $39 \%$ in a meta-analysis. However, considerable heterogeneity was observed between studies. ${ }^{34}$ The inconsistency between this and other studies could be attributed to small sample sizes and a lack of a standardized definition for suspected nodal involvement.

The favourable performance of surface coil MRI in our study may be due to recent advances in fast spin-echo sequences and pelvic phased-array surface coils that have significantly improved the signal-to-noise ratio, and tempor- al and spatial resolution. ${ }^{21,35}$ However, these data should be used for hypothesis generation as several limitations preclude generalization. As with all diagnostic procedures, inter-rater reliability must be ascertained prior to recommending use in general practice. Allan and colleagues compared diagnostic accuracy of pelvic MRI between a "specialist" compared with a "general" radiologist and found a significant difference in accuracy. ${ }^{32}$ Certainly, the interpretation of the MRI images is subjective and we suspect the expertise of the radiologist to be an important factor in the validity of this diagnostic test. In our series, the radiologist had a special interest in pelvic MRI and no sub-specalized training in prostatic imaging.

The relatively small sample size of this series should also be considered. The analysis was performed evaluating each prostate lobe (left and right) independently. In doing so, our risk group analysis may have been affected since clinical stage and risk group determinations were based on the prostate gland as a whole. For instance, there were 4 patients categorized in the intermediate-risk group and 7 patients in the high-risk group with tumour localized only to one side, however, both samples were considered to be intermediate- and high-risk, respectively. This may explain why we found no significant differences between intermediate- and high-risk groups. It is difficult to assess the degree to which the side-specific examination may have affected our group analysis, but the overall result is likely unchanged since pathological and radiological determinations are performed independent of clinical stage.

\section{Conclusion}

Location-specific stage prediction of prostate cancer is important for pre-treatment planning and intra-operative decision-making. Our data suggest that pelvic phased-array surface coil MRI performs well in patients with high-risk and select intermediate-risk prostate cancer. It is reasonably accurate in confirming the presence of large tumours in the prostate and detecting extraprostatic extension. A large multi-institutional study of surface coil MRI will better define the performance of this test and will help define the role of $\mathrm{MRI}$ in preoperative assessment of prostate cancer.

*Division of Urology, Department of Surgery, University of Ottawa, Ottawa, ON; †Department of Radiology, University of Ottawa, Ottawa, ON; ₹0ttawa Health Research Institute, University of Ottawa, Ottawa, ON

Competing interests: None declared.

This paper has been peer-reviewed. 
Kim et al.

\section{References}

1. Jemal A, Tiwari RC, Murray T, et al. American Cancer Society: Cancer statistics 2004. CA Cancer I Clin 2004:54:8-29.

2. Hricak H, Choyke PL, Eberhardt SC, et al. Imaging prostate cancer: a multidisciplinary perspective. Radiology 2007:243:28-53

3. Akin 0, Sala E, Moskowitz CS, et al. Transition zone prostate cancers: features, detection, localization, and staging at endorectal MR imaging. Radiology 2006;239:784-92.

4. Yu KK, Hricak H, Alagappan R, et al. Detection of extracapsular extension of prostate carcinoma with endorectal and phased-array coil MR imaging: multivariate feature analysis. Radiology 1997;202:697702.

5. Chelsky MJ, Schnall MD, Seidmon EJ, et al. Use of endorectal surface coil magnetic resonance imaging for local staging of prostate cancer. J Urol 1993;150:391-5.

6. Rorvik J, Halvorsen OJ, Albrektsen G, et al. MRI with an endorectal coil for staging of clinically localised prostate cancer prior to radical prostatectomy. Eur Radiol 1999;9:29-34.

7. Siegelman ES. Magnetic resonance imaging of the prostate. Semin Roentgenol 1999;34:295-312.

8. Greene FL, Page DL, Fleming ID, et al. AJCC Cancer Staging Manual, 6th ed. New York, NY: SpringerVerlag; 2002.

9. Scheidler J, Hricak H, Vigneron DB, et al. Prostate cancer: localization with three-dimensional proton MR spectroscopic imaging-clinicopathologic study. Radiology 1999;213:473-80.

10. Engelbrecht MR, Huisman HJ, Laheï RJ, et al. Discrimination of prostate cancer from normal peripheral zone and central gland tissue by using dynamic contrast-enhanced MR imaging. Radiology 2003;229:248-54.

11. Wefer AE, Wefer J, Frericks B, et al. Advances in uroradiological imaging. BJU Int 2002;89:477-87.

12. Jager GJ, Ruijter ET, van de Kaa CA, et al. Dynamic TurboFLASH subtraction technique for contrast-enhanced MR imaging of the prostate: correlation with histopathologic results. Radiology 1997;203:645-52.

13. Coakley FV, Qayyum A, Kurhanewicz J. Magnetic resonance imaging and spectroscopic imaging of prostate cancer. J Urol 2003;170:569-75

14. Ohori M, Kattan MW, Utsunomiya T, et al. Do impalpable (TIc) cancers visible on ultrasound differ from those not visible? J Urol 2003;169:964-8.

15. Rifkin $M D$, Zerhouni $E A$, Gatsonis $C A$, et al. Comparison of magnetic resonance imaging and ultrasonography in staging early prostate cancer. Results of a multi-institutional cooperative trial. N Engl J Med 1990;323:621-6.

16. Biondetti PR, Lee JK, Ling D, et al. Clinical stage B prostate carcinoma: staging with MR imaging. Radiology 1987;162:325-9.

17. Carrol CL, Sommer FG, McNeal JE, et al. The abnormal prostate: MR imaging at $1.5 \mathrm{~T}$ with histopathologic correlation. Radiology 1987; 163:521-5.

18. Bezzi M, Kressel HY, Allen KS, et al. Prostatic carcinoma: staging with MR imaging at 1.5 T. Radiology 1988:169:339-46
19. Schnall MD, Lenkinski RE, Pollack HM, et al. Prostate: MR imaging with an endorectal surface coil. Radiology 1989:172:570-4.

20. Engelbrecht MR, Jager GJ, Laheij RJ, et al. Local staging of prostate cancer using magnetic resonance imaging: a meta-analysis. Eur Radiol 2002;12:2294-302.

21. Sonnad SS, Langlotz CP, Schwartz IS. Accuracy of MR imaging for staging prostate cancer: a meta-analysis to examine the effect of technologic change. Acad Radiol 2001;8:149-57.

22. Kirkham AP, Emberton M, Allen C. How good is MRI at detecting and characterising cancer within the prostate? Eur Urol 2006:50:1163-74

23. Kattan MW, Eastham JA, Wheeler TM, et al. Counseling men with prostate cancer: A nomogram for predicting the presence of small moderately differentiated, confined tumors. J Urol 2003;170:1792-7.

24. Partin AW, Kattan MW, Subong EN, et al. Combination of prostate-specific antigen, clinical stage, and Gleason score to predict pathological stage of localized prostate cancer. A multi-institutional update. JAMA 1997;277:1445-51

25. Gancarczyk KJ, Wu H, Mcleod DG, et al. Using the percentage of biopsy cores positive for cancer, pretreatment PSA, and highest biopsy Gleason sum to predict pathologic stage after radical prostatectomy: the Center for Prostate Disease Research nomograms. Urology 2003;61:589-95.

26. Ohori M, Kattan MW, Koh H, et al. Predicting the presence and side of extracapsular extension: a nomogram for staging prostate cancer. J Urol 2004;171:1844-9.

27. Steuber $T$, Graefen $M$, Haese $A$, et al. Validation of a nomogram for prediction of side specific extracapsular extension at radical prostatectomy. J Urol 2006;:175:939-44.

28. Cagiannos I, Karakiewicz P, Eastham JA, et al. A preoperative nomogram identifying decreased risk of positive pelvic lymph nodes in patients with prostate cancer. J Urol 2003;170:1798-803.

29. Wang L, Mullerad M, Chen HN, et al. Prostate cancer: incremental value of endorectal MR imaging findings for prediction of extracapsular extension. Radiology 2004;232:133-9.

30. Wang L, Hricak H, Kattan MW, et al. Prediction of seminal vesicle invasion in prostate cancer: incremental value of adding endorectal MR imaging to the Kattan nomogram. Radiology 2007;242:182-8.

31. Pauker SG, Kassirer JP. The threshold approach to clinical decision making. N Engl J Med 1980;302:1 109-17.

32. Allen DJ, Hindley R, Clovis $S$, et al. Does body-coil magnetic-resonance imaging have a role in the preoperative staging of patients with clinically localized prostate cancer? BJU Int 2004:94:534-8.

33. Engelbrecht MR, Jager GJ, Laheii RJ, et al. Local staging of prostate cancer using magnetic resonance imaging: a meta-analysis. Eur Radiol. 2002;12:2294-302.

34. Hövels AM, Heesakkers RA, Adang EM, et al. The diagnostic accuracy of CT and MRI in the staging of pelvic lymph nodes in patients with prostate cancer: a meta-analysis. Clin Radiol 2008:63:387-95.

35. Kier R, Wain S, Troiano R. Fast spin-echo MR images of the pelvis obtained with a phased-array coil: value in localizing and staging prostatic carcinoma. AJR Am J Roentgenol 1993;161:601-6.

Correspondence: Dr. Brian Kim, Department of Surgery, Division of Urology, Ottawa University Hospital, 1053 Carling St., Ottawa, ON K1Y 4E9; fax: 613-761-5305; briani_kim@rogers.com 